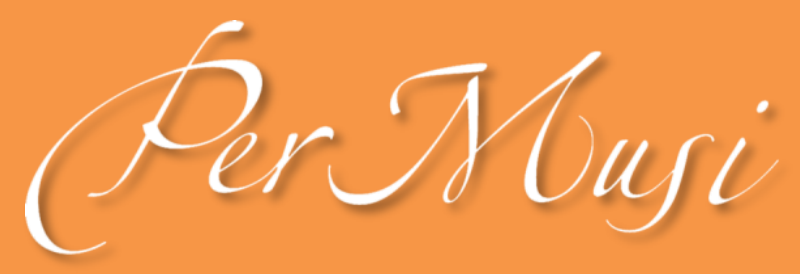

elSSN 2317-6377

\title{
Interpretação vocal e processos de criação
}

\author{
Lucila Tragtenberg \\ https://orcid.org/0000-0002-8716-0001 \\ Pontifícia Universidade Católica de São Paulo, Departamento de Artes \\ lucilatragtenberg@gmail.com
}

SCIENTIFIC ARTICLE

Data de submissão: 30 aug 2021

Data de aprovação final: 17 oct 2021

Resumo: Este artigo aborda aspectos ligados aos processos de criação de cantores, trazendo também seu diálogo com o trabalho de criação dos compositores. Isso inclui as questões de Umwelten (Vieira 2008, 2009), sujeito e self Peirceano (Colapietro 1989, 2003), o conceito de mestiçagem (Laplantine e Nouss 2002), suportes (escritos ou oralizados), e a percepção ecológica, tal como conceituada por J. Gibson (1979). Para contribuir com a reflexão sobre esses aspectos, selecionamos alguns depoimentos de cantores acerca de suas criações interpretativas da Canção de Amor de Villa-Lobos, buscando trazer à luz conhecimentos sobre seus processos criativos, sempre inacessíveis ao público. Esses depoimentos constam de nossa tese de doutorado defendida na linha de pesquisa de Processos de Criação. Recorremos ainda, a recursos da crítica de processos e redes da criação de Cecilia Salles (2006, 2008, 2010, 2011).

Palavras-chave: Processos de criação; cantores; compositores; Umwelt; Self.

\section{TITLE: VOCAL INTERPRETATION AND CREATION PROCESSES}

Abstract: This paper addresses aspects related to the singer's creation processes and brings also their dialogue with the composers' creation work, which includes the issues of Umwelten (Vieira 2008, 2009), the Peircean concepts of subject and self (Colapietro 1989, 2003), the concept of miscegenation (Laplantine and Nouss 2002), supports (written or oralized), and ecological perception, as conceptualized by J. Gibson (1979). In order to contribute to the reflection on these aspects, some testimonies from singers about their interpretative creations of the Canção de Amor [Song of Love], by Villa-Lobos, were brought. The objective is to expose the details of their creative processes, otherwise inaccessible to the public. These testimonies are part of our doctoral thesis defended in the line of research of Creative Processes. We also refer to resources from the processes criticism and nets of creation by Cecilia Salles (2006, 2008, 2010, 2011).

Keywords: Creation processes; Singers; Composers; Umwelt; Self.

(C) (1) 


\section{Interpretação vocal e processos de criação}

Lucila Tragtenberg, Pontifícia Universidade Católica de São Paulo, lucilatragtenberg@gmail.com

\section{Introdução}

Iniciamos este artigo com a noção de reciprocidade criativa, que se refere aos processos de criação da interpretação, realizados por cantores. Denominamos e discutimos esse termo em nossa dissertação em Canto. Ali, estudamos a relação de reciprocidade criativa entre cantor e compositor, através de análises das entrevistas que realizamos com três cantores de nosso cenário musical. Elas trouxeram informações acerca da criação de suas interpretações de peças musicais contemporâneas. Estas apresentavam aspectos de indeterminação musical e indicações cênicas. Tais aspectos ampliam o papel criativo do intérprete da música de concerto e tornam evidente a realidade da criação na interpretação vocal, pois o cantor deverá criar alturas, ritmos, o que torna explícito seu papel criativo. Esta característica nos facilitou a aproximação investigativa ao complexo fenômeno da criação da interpretação vocal.

Assim, naquele trabalho focamos a relação de reciprocidade criativa que propusemos e que compreendíamos, como o processo de criação desenvolvido pelo cantor a partir dos elementos criados e grafados na partitura pelo compositor. O termo "reciprocidade" indica uma relação horizontal no trânsito criativo, que acreditamos que se estabeleça entre compositor e cantor. Discutimos, naquela ocasião, várias evidências desse trânsito horizontal relacional que permite a inclusão da criação no trabalho de ambas as partes. No caso do cantor, ela se dá quando ele entra em contato com o que o compositor criou e grafou na partitura e, a partir disso, realiza a sua criação interpretativa da música.

E então, em nosso doutorado em Processos de Criação, buscamos nos aprofundar em camadas de complexidade nas investigações dos processos de criação da interpretação vocal, dimensionando-os em uma rede de processos de criação (Salles 2006) formada por conexões entre aspectos relacionais e históricoculturais entre compositor e cantor, que incluem a partitura, o self semiótico (Colapietro 1989) e a percepção ecológica (Gibson 1979). Foi vital incorporar à discussão e à rede o conceito de mestiçagem, tal como discutido por Laplantine e Nouss (2002), que aponta para o sentido e qualidades do trânsito relacional entre quarteto compositor, cantor, partitura e informações histórico-culturais e biográficas acerca do compositor, aprofundando a noção de reciprocidade criativa proposta em nosso mestrado.

A escolha da pesquisa sobre um outro gênero musical no doutorado (a canção de câmara, e não a música contemporânea, como no mestrado), cujos parâmetros não possibilitam a clara evidência da dimensão de criação no trabalho interpretativo, levou-nos à possibilidade de evocar a presença da criação em aspectos possivelmente mais amplos e menos evidentes, tecida nos processos da interpretação vocal. Focalizamos, assim, a Canção de Amor, de Heitor Villa-Lobos, e aspectos de seus processos de criação realizados por cinco 
cantores que atuam no meio musical brasileiro e internacional, a saber, três sopranos, um tenor e um baixobarítono. ${ }^{1}$ Neste artigo, trazemos alguns de seus depoimentos que se dirigem a aspectos relacionais. Eles incluem cantor e compositor quanto aos suportes de criação, às escritas manuscritas e corporais com seus Umwelten e à noção de mutualidade, affordance, invariantes e variantes presentes na percepção ecológica, correlacionadas à dimensão da partitura.

Pesquisas sobre os processos de criação de cantores no Brasil é ainda um campo recente. Elas tiveram início, pelo menos, a partir de duas décadas. Quanto aos processos criativos dos compositores, já existem muitas pesquisas durante ao menos, um século. A questão da criação no trabalho do cantor necessita ainda, de um número maior de focos de luzes sobre ela. Inclusive o aspecto da expressão na música de concerto muitas vezes se reduz. Em Understanding the psychology of performance, Eric Clarke (2005) evidencia que a "expressão" na performance musical, apesar de ter grande importância, muitas vezes é ignorada. Segundo Clarke, fica-se surdo em relação a sua presença. Essa ambiguidade existente em torno do aspecto expressivo, ainda em nossos tempos, estende-se à questão do dimensionamento da face criativa no trabalho do intérprete.

Refletiremos, a seguir, a respeito de suportes para a criação no trabalho de cantor e compositor. Serão apresentadas evidências de que, de modo diverso aos compositores, os cantores não costumam anotar aspectos de sua criação nas partituras que utilizam para preparar as músicas que irão cantar, e essa situação singular pede por reflexões acerca de si.

\section{Suportes e criação}

Ampliando os acessos às criações interpretativas, serão discutidos neste momento, os possíveis suportes usados pelos cantores nesta prática. No entanto, o trabalho processual de criação realizado por cantores não possui, geralmente, um suporte material em que seus aspectos (ainda que parciais) se fixem, materializados, o que possibilitaria acesso a eles, tal como se tem aos rascunhos e anotações de compositores, cineastas, escritores e artistas das artes visuais e do teatro. Sabemos que cantores não utilizam cadernos ou diários como suporte, nos quais armazenariam algum tipo de material sobre experimentações e reflexões de ordens diversas (a respeito de si, do entorno, de objetos).

Existem os cadernos de artista que são analisados na área de artes visuais e ainda, pela vertente da crítica genética, entre outros campos críticos. Em música, um exemplo expressivo é o dos cadernos de rascunhos e anotações do compositor Beethoven, que foram objeto de estudo do maestro e compositor L. Bernstein. Bernstein selecionou alternativas não utilizadas pelo compositor da Quinta Sinfonia e as analisou. Esse trabalho teve ampla divulgação na mídia televisiva, tendo sido apresentado nos anos 1950 em Omnibus na televisão americana. ${ }^{2}$

${ }^{1}$ Realizamos, em nossa tese de doutorado, entrevistas individuais com os cantores, utilizando a partitura da Canção de Amor e evocando, através dela, seus processos de criação, seguidas por reflexões à luz de nosso referencial teórico. Cada um dos cantores nos autorizou a utilizar suas entrevistas e respectivas análises em publicações decorrentes da tese.

${ }^{2}$ Lewis Lockwood também estudou a vida e a obra de Beethoven. Em seu livro Beethoven: a música e a vida, o autor indica a existência e a natureza processual criativa do que foi anotado pelo compositor: "Em vez de 
Nas partituras musicais utilizadas no período de preparação da obra, na maior parte das vezes, o que o cantor costuma anotar são apenas algumas respirações a serem feitas, além de traduções de palavras de outros idiomas. Essa realidade é explicitada por duas das sopranos e pelo baixo-barítono entrevistados para nossa tese:

Soprano 1: Não [anoto] a interpretação. Anoto respiro, e anoto às vezes a palavra, aquilo que eu quero valorizar, ou que eu preciso de uma ajuda para entender melhor. Mas isso eu anoto quando eu estou estudando pela primeira vez, não é uma anotação que eu fico toda hora refazendo. (Tragtenberg 2012, 86).

Soprano 2: [...] como eu te falei, eu marco muito pouca coisa nas partituras. (Tragtenberg 2012, 86).

Soprano 1: É que eu não tenho nada... Eu quase não anoto, sabia? Só anoto quando é coisa de texto, quando é uma tradução, uma palavra que eu não conheça. Eu tenho muito respiro só. (Tragtenberg 2012, 85).

Baixo-barítono: Quando se trata de trecho em língua estrangeira, anoto o significado (tradução) de cada palavra e faço um documento com a tradução linha por linha, para consulta específica. Mas não anoto aspectos interpretativos na partitura. (Tragtenberg 2012, 86).

Por vezes, o cantor escreve indicações na partitura, visando chamar sua própria atenção para algum trecho específico (como indicado pela soprano 1), ou ainda para algo mais difícil de caráter rítmico ou melódico, ou algo quanto à necessidade técnica de emissão da voz. Entre outros sinais que cada intérprete pode criar, de acordo com o que considerar chamativo para sua atenção, identificamos nas partituras de correpetidores pianistas a utilização frequente do desenho de um par de óculos, com a finalidade de chamar sua atenção para um trecho importante.

Em relação aos cantores, podemos encontrar anotações na partitura quanto à pronúncia de determinadas palavras e aos elementos musicais. Essas anotações podem ser advindas de indicações e observações de maestros ou pianistas acompanhadores que preparam a música com o cantor. Elas podem também ser oriundas de um ensaio de grupo musical que se apresentará em conjunto, situação em que seus integrantes necessitam entrar em comum acordo quanto à forma da peça (voltas, etc.). Pode-se, por certo, inferir algo por meio das marcações na partitura, como as respirações realizadas pelo cantor em toda a música. Em nossa pesquisa de doutorado, elas nos trouxeram informações complementares a respeito dos processos criativos de alguns dos cantores. Mas isso somente foi possível devido ao contato anterior que tivemos com seus relatos, nas entrevistas, sobre especificidades interpretativas intrínsecas a eles. Sem esse contato direto com o cantor, o acesso unicamente às poucas anotações possui um alto nível de imprecisão. São raras as

destruir as ideias preliminares de suas obras, ou de permitir que se dispersassem e se perdessem - como fizeram quase todos seus antecessores, de Bach a Mozart -, Beethoven manteve intacta a maior parte do material inicial de suas composições, o que lhe permitia, a qualquer momento, rever os detalhes de seu desenvolvimento, refletido não só nas obras terminadas, mas também no seu processo formativo." (Lockwood 2005, 39-40). 
informações que podem ser retiradas dali quando tomadas de modo isolado, em especial quando se leva em conta o fato de que, geralmente, não são anotadas nas partituras ou em outros suportes as possibilidades, reflexões, experimentações, escolhas realizadas, discussões dialógicas e tendências vivenciadas nos processos criativos da interpretação vocal. Porém, tais aspectos se mostram vitais para se adentrar camadas de sua complexidade, levando-se em conta que "[...] por trás de uma substituição, eliminação, uma adição, há, certamente, todo um complexo processo envolvendo critérios e razões. Fazer modificações é optar." (Salles 2008, 48). E, ainda, tal como explicitado pelo tenor entrevistado em relação ao seu trabalho criativo, "[...] você construiu um mundo ali" (Tragtenberg 2012, 86), aludindo à presença de filtros singulares de mediação como a imaginação, a memória, a sensação, a emoção e os sentimentos. Esses elementos são participantes ativos junto aos critérios e razões utilizados pelos cantores, em momentos de criação e de modificação de suas próprias criações. Não nos esqueçamos que eles ocorrem, efetivamente, tanto nos ensaios, como nos momentos da performance, da apresentação frente ao público.

Assim, nos orientamos pelos relatos orais dos cantores sobre seus encontros com os signos presentes na partitura para buscar as suas vivências criativas. Tomamos como um dos pontos investigativos a noção de criação como transformação (Salles 2010), constituída por relações transformadoras de diversas ordens, participantes das redes criativas dos cantores. Pesquisamos nelas a "[...] natureza destes vínculos, que podem ser observados sob o ponto de vista das singularidades das transformações operadas" (Salles 2010, 26). Essas transformações incluíram os signos grafados na partitura e os aspectos singulares conferidos a eles pelos cantores. Tal dimensão realista é importante para a investigação dos processos criativos vocais. Sublinhamos ainda que elementos de contextos históricos, sociais, culturais e biográficos relativos aos cantores, ao compositor e à peça musical (ou seja, informações que envolvem ambientes circundantes à tríade cantor, partitura e compositor) também estão presentes nas conexões dos processos criativos da interpretação vocal.

Se os cantores, nos processos de criação, pouco recorrem a suportes externos para anotações que contribuam para o próprio desenvolvimento processual, tal como vimos, elas ainda ocorrem, em "escritas" corporalizadas. Abordaremos esse ponto a seguir.

\section{Escrita, grafia e corpo}

O compositor Edson Zampronha aponta como marcas sígnicas a escritura, a grafia e a escrita no contexto da composição e da improvisação musical, sob aspectos da semiótica peirceana. $O$ autor se utiliza das palavras "grafia" e "escrita" para indicar o trabalho do intérprete ${ }^{3}$ :

Compor um quarteto de cordas não é simplesmente se utilizar de um meio de produção musical, mas interagir com toda uma densidade de marcas que este meio já possui em si. Da mesma forma como o corpo do músico é uma escrita, o quarteto de cordas traz em si

\footnotetext{
${ }^{3}$ As "marcas" citadas relativas à instrumentação não serão comentadas aqui devido à amplitude do tema. Ressaltamos apenas sua presença e sua dimensão.
} 
mesmo o conjunto denso de marcas que o caracteriza[...] O próprio corpo é uma grafia de gestos e hábitos interpretativos. (Zampronha 1998, 219).

A expressão "corpo do músico", citada acima, diz respeito ao corpo do intérprete, mas parece também se referir ao corpo do compositor (com consequências diferentes em relação a este, como será abordado adiante). É o que indica o autor quando reflete sobre a complexidade das "marcas" atuadas por signos no ato de compor: "Se regredirmos para trás do momento em que a partitura é realizada pelo compositor só encontraremos marcas (hábitos, memórias, percepções, outras grafias, remissões[...])" (Zampronha 1998, 212).

Denise Garcia indica também o que denominou uma escuta interna, com um ritmo específico, que, por fim, tornou-se importante no todo de Poema Sujo, sua composição para soprano e trompa: "[...] assim que bati os olhos no poema, escutei um ritmo ternário, do qual não me livrei enquanto não coloquei no papel. Esse desenho rítmico irrompe no início da peça, retornando várias vezes em uma espécie de voragem vertiginosa..." (Garcia apud Ferraz 2007, 59-60).

Mas, no complexo processo de composição, essas "marcas" corporais do compositor, referidas por Zampronha e relatadas nas percepções de Denise Garcia, são similares à prática de criação do cantor, quando este se utiliza de "[...] hábitos, memórias, percepções, outras grafias, remissões. [..]" (Zampronha 1998, 212)". No entanto, elas ocorrerão para o compositor em outros suportes: nas interações com o papel e nos softwares (usados na música eletroacústica e eletrônica).

A dimensão do desenvolvimento processual das escritas do cantor e do compositor possui, assim, naturezas diversas nas construções das obras. O cantor desenvolverá escritas em suas habilidades físicas corporais, tendo em vista a realização da performance ao vivo, em encontro futuro com o público. O compositor as desenvolverá - a partir da mobilização corporal - em interações diretamente grafadas no papel, na partitura, ou no computador. O compositor tem ainda em vista, o encontro dessa partitura com o cantor que levará a música ao público em tempo real, e tem também a perspectiva de sua difusão eletroacústica, sem a intermediação de um intérprete. Soma-se a isso ainda o fato de que o papel realmente acolhe, tal como atestam muitas publicações, informações dos processos criativos do compositor: rasuras encontradas em manuscritos, palavras sobre caminhos musicais, esboços de motivos.

Dito de outro modo, mais específico: enquanto o trabalho processual de criação do compositor lida com marcas e escritura da escrita ${ }^{4}$ no papel, em cadernos/partituras, ou no computador, o cantor não se utiliza de outra dimensão física além de seu próprio corpo para desenvolvimento e escrita da criação interpretativa e para a performance ao vivo. Assim, podemos compreender, em parte, a dimensão significativa da utilização do espaço corporal como espaço dialógico de escritas por parte do cantor, mais do que o espaço dos papéis (a partitura ou os cadernos).

\footnotetext{
${ }^{4}$ Zampronha promove uma discussão profunda acerca do que apresenta como a 'escritura da escrita' no processo de escrita composicional, que pode ser acessada em Notação, representação e composição: um novo paradigma da escritura musical, editado em 2000 pela Editora Annablume.
} 


\section{Umwelten e self}

Há um aspecto importante, relativo ao que foi discutido quanto às grafias e escrituras envolvendo cantores e compositores, e que devido a sua abrangência poderá vir a ser desenvolvido em futuras pesquisas. Se trata da diversidade, mencionada anteriormente, que existe na prática criativa de intérprete e compositor, e que parece apontar para a possibilidade de diversidade de Umwelten criativos.

Contextualizando a semiose da "escrita" em seus possíveis aspectos, trazemos o conceito de Umwelt, de J. von Uexküll, "[...] a base biológica da teoria dos signos ou Semiótica, no sentido peirceano" (Vieira 2008, 79, grifo do autor). O termo alemão pode ser traduzido como "em [Um] mundo [die Welt]", ou "(n)o mundo como tal", "meio-ambiente", "mundo em torno", "mundo circundante". O conceito se refere à interface entre a realidade e o sistema vivo nas características específicas das espécies, desenvolvidas a partir da interação com a realidade. E "[...] esta interface está aí, é a ponte, a intersecção entre objetividade e subjetividade. Funciona como se cada espécie tivesse um mundo particular, tivesse um universo particular." (Vieira 2009, 15). As diferenças auditivas entre o ser humano e alguns animais (como morcegos e cachorros) mostram claramente uma característica de diversidade de Umwelt. No entanto, Vieira indica que houve expansões importantes no Umwelt biológico humano: “Parece-nos claro que nossa complexidade já adicionou um Umwelt psicológico, social e cultural àquele biológico, pela expansão da chamada noosfera e todo nosso arsenal comunicacional e semiótico." (Vieira 2008, 80-81).

A dimensão relacional do compositor com papéis e softwares em seus processos de criação - incluindo a consciência da condição final deles (a partitura e, indiretamente, o público) - certamente é de ordens diversas e inclui demandas diferentes das que existem em relação à ênfase corporal e à predição de performances ao vivo, presentes nos processos de criação do cantor. Se num primeiro momento é possível considerar que o cantor e o compositor tenham um Umwelt comum (em uma macrodimensão, o gênero humano, e em uma microdimensão, as "escritas" musicais), em um segundo momento, como aponta Jorge Vieira $(2008,85)$ :

[...] é importante, como feito e proposto por Uexküll, que pensemos na possibilidade de uma diversidade de Umwelten dentro de nossa espécie, com diferenciações que podem estar presentes, inclusive, nas habilidades neurológicas que caracterizam cientistas e os artistas ou mesmo em subclasses internas a esses segmentos. Estilos artísticos, habilidades empíricas ou teóricas, etc., podem ser índices dessas diferenciações. (Vieira 2008, 85)

Entretanto, essa diversidade não possui, a nosso ver, aspectos negativos; ao contrário, ela nos parece operar em um nível de complementaridade produtivo para a criação musical. Podemos compreendê-la como diversos pontos de vista de desenvolvimentos da criação. A presença enfática da corporalidade no trabalho do cantor participa ativamente de seus processos de criação, uma criação às avessas, que imprime aspectos diversos dos da materialidade do papel e do computador existentes nos processos de criação do compositor, os quais solicitam deste, habilidades e competências de outras ordens.

Partindo de tais singularidades, contextos e práticas determinadas, estabeleceremos neste momento um diálogo entre a criatividade e os atravessamentos do sujeito e do self pelas esferas histórica, social e cultural, 
e aspectos de obras do semioticista Vincent Colapietro $(1989,2003)^{5}$ sobre instâncias da subjetividade, do self e do sujeito na obra de C. S. Peirce. Com base na dimensão do sujeito inscrita nas "escritas" de criações musicais - a interpretação e a composição - parece ser possível nos aproximarmos ainda mais da realidade de criação do cantor, dialogando com a compreensão de self no contexto da teoria peirceana. Para tanto, retomamos a fala de Peirce através de Colapietro: “[...] o self é ele mesmo um signo. O sujeito em seu mais profundo íntimo é ele mesmo uma forma de semiose"6 (Peirce apud Colapietro 1989, 37, tradução nossa).

Na abordagem peirceana da subjetividade humana, temos signos em semiose: "Nossa leitura de Peirce como um explorador de signos assegura a promessa de adquirir uma forma crucial de letramento; nomeadamente, nossa habilidade de nos lermos como produtos, processos e fontes de semioses. Os signos estão lá, se apenas nós pudermos decifrá-los. ${ }^{7 "}$ (Colapietro 1989, 47, tradução nossa). Lembramos que a semiose é um processo de contínua interpretação de signos em signos. Colapietro comenta acerca da dimensão comunicativa do self individual, o qual se mostra em seu mais íntimo, não como uma esfera privada, mas como um agente comunicativo, e essa dimensão é crucial na compreensão do papel do cantor.

A esfera comunicacional situa o self como "[...] a fonte de quem o discurso flui e o ser para quem o discurso é endereçado... alguém sobre quem algo é dito" (Colapietro 2003, 38, tradução nossa) ${ }^{8}$. O autor indica seu trânsito com sujeitos e instâncias culturais, históricas e sociais entrelaçadas em materialidades, pluralidades em movimento, afastando a perspectiva do subjetivismo abstrato, que indicaria sua situação de isolamento, de difícil acesso. Colapietro caracteriza o self como um agente comunicativo, contrariando a noção de isolamento do sujeito: "[...] marca a mudança do self em si mesmo para os sutis e ainda precários modos em que o outro é no self e o self é no outro. A alteridade está inscrita na subjetividade." (Colapietro 2003, 71, tradução nossa).

Outras falas também atravessam o self:

O self como falante é alguém através de quem/outros falam. [...] O sujeito é entre outras coisas, um meio através do qual forças e pessoas outras que não o sujeito, falam. Este fato sobre o sujeito demanda que repensemos o sentido no qual o self é tido como a fonte do pensamento e ação, sentimento e sonhos. ${ }^{9}$ (Colapietro 1989, 38, tradução nossa).

\footnotetext{
${ }^{5}$ Peirce's approach to the self (1989) e "The loci of creativity: fissured selves, interwoven practices" (2003). 6 "[...] the self is itself a sign. The subject in its innermost being is itself a form of semiosis." (Peirce apud Colapietro 1989, 37).

7 "Our reading of Peirce as an explorer of signs holds the promise of acquiring a crucial form of literacy; namely our ability to read ourselves as products processes, and sources of semiosis. The signs are there, if only we can decipher them." (Colapietro 1989, 47).

8 "[...] a source from whom discourse flows and a being to whom discourse is addressed.... Someone about whom something is said." (Colapietro 2003, 38).

9 "The self as speaker is someone through whom/others speak... The subject is among other things, a medium through which forces and persons other than the subject speak. This fact about the subject demands that we rethink the sense in which the self is a source of thought and action, feeling and dreams." (Colapietro 1989, 38).
} 
Assim, tal self corporal passa a se constituir em uma instância de semiose. Vendo por esse ângulo, o sujeito é, ele mesmo, constituído em processos semiósicos e, ao mesmo tempo, em estado resultante de crescimento constante. Podemos incluir nessa paisagem o compositor e o cantor.

As "escritas internas" acima citadas também podem ser dimensionadas de modo mais específico como signos que interagem com signos constituintes do self, incluindo, de modo inerente, o inacabamento e o crescimento em continuum. As "escritas" relativas ao compositor e ao cantor não têm um caráter fixo, estático. Ao contrário, elas se desenvolvem com a presença da intersubjetividade, em um processo dinâmico, como no diálogo ficcional com o compositor, revelado nos relatos das entrevistas sobre os processos de criação da Canção de Amor $^{10}$ de Villa-Lobos:

Soprano 1: [Acerca de algumas passagens difíceis em geral em músicas diversas] Fico perguntando em alguns momentos, porque ele fez aquilo, aquela nota, tão difícil. [Em relação à Canção de Amor] Mas eu acho que ela não é para ter o tempo inteiro lento. Tem que haver um grande contraste, quando ele pede aquela mudança ali no Piu Mosso. (Tragtenberg 2012, 93).

Soprano 3: [...] porque está tudo tão explícito na letra que o que te resta mesmo é prestar atenção no que o compositor quis com relação à dinâmica; então ele já diz tudo. Num momento mais suave, que a palavra é mais doce, num momento em que ela depois muda um pouco de andamento... (Tragtenberg 2012, 93).

Soprano 3: Ele [o compositor] finge que é uma coisa que é outra. (Tragtenberg 2012, 93).

Baixo-barítono: Quando a gente fala de ler a partitura, não só ler as frases, as melodias, mas ler o acompanhamento, ler a dinâmica, ler muitas vezes, no caso de ópera, ou às vezes até mesmo em música de câmara, ele muda, ele coloca a sugestão emocional para determinados lugares. Por exemplo, aqui, nós não temos isso, mas existem situações em que ele diz "triste, com melancolia", quer dizer, ler essas rubricas. (Tragtenberg 2012, 93).

Soprano 2: [...] é, eu prefiro respirar antes do ah, aliás, ele pede para ligar. (Tragtenberg $2012,93)$

Tenor: Ele faz um Ré e agora ele faz um Mi direto. TARIII (trecho da letra "pela dor") ele dá uma aliviada. A sensação que eu tenho, ele alivia. [Quanto ao final da peça] É, porque aqui a terminação também você vê que é totalmente sublimada. Ele não termina nem no grave, ele só deixa ecoar. (Tragtenberg 2012, 93).

Com relação à criatividade, tomando-se em conta a expressividade do sujeito pós-moderno, cindido, situado em múltiplas localizações entrelaçadas, de cunho histórico, social e cultural (porém não de modo determinista), Colapietro propõe que a manifestação da criatividade seja reconhecida de forma

${ }^{10}$ A Canção de Amor, de Villa-Lobos, pode ser ouvida na íntegra, com interpretação da soprano Leila Guimarães, em: <https://www.youtube.com/watch?v=sOyxdOEqOrg>. 
descentralizada, em decorrência desse descentramento do sujeito. Assim, a criatividade não estaria centralizada no sujeito, mas sim nos diversos locais em que suas práticas acontecem, tal como explicitado no título do artigo "Os locais da criatividade: eus fissurados, práticas entrelaçadas" (Colapietro 2003, 59).

Podemos perguntar: quais seriam as localizações de tais práticas entrelaçadas? Entendendo de modo amplo, trata-se de uma rede de práticas de significação que, ao serem focalizadas, transferem assim a atenção do sujeito/self criativo enclausurado em si para seu entrelaçamento com práticas situadas em um determinado contexto histórico, social e cultural. Podemos compreender a prática de criação do compositor e do cantor como sendo uma delas. Tais práticas passam a ter um papel central, transformando-se em foco de reflexões teóricas:

As mais importantes críticas contemporâneas da subjetividade humana consistem em nada menos que o descentramento do sujeito [...] as críticas de Peirce, Lacan, Foucault e Derrida (para nomear apenas quatro dos mais importantes teóricos deste olhar) se dirigem em direção ao descentramento do sujeito [...] essas críticas transportam as práticas (especialmente uma matriz entrelaçada de práticas significantes) das margens para o centro da atenção teórica. Resumindo, estabelecem a centralidade da prática. (Colapietro $2003,68,69$, tradução nossa). ${ }^{11}$

Especificando ainda mais:

No meu julgamento, a mais importante destas implicações é o deslocamento decisivo da atenção teórica para as questões da prática: o descentramento do sujeito significa, sobretudo, a centralidade das práticas, em sua materialidade, pluralidade, historicidade e, assim, mutabilidade. (Colapietro 2003, 64, grifo nosso, tradução nossa). ${ }^{12}$

O fazer artístico do cantor e sua postura de diálogo com o trabalho do compositor, tal como vêm sendo compreendidos neste artigo, partindo da crítica de processos (Salles 2010), compartilha a delimitação acima citada, pois, em nosso trabalho, "A arte está sendo abordada sob o ponto de vista do fazer, dentro de um contexto histórico, social e artístico. Um movimento feito de sensações, ações e pensamentos, sofrendo intervenções do consciente e inconsciente." (Salles 2011, 34).

Entretanto, intervenções conscientes e inconscientes no fazer artístico e a materialidade das práticas entrelaçadas possuem, no âmbito do sujeito encarnado, um aspecto expressivo, ressaltado por Colapietro, que é importante para a natureza do trabalho de criação, tanto do compositor, como do cantor:

11 "The most important contemporary critiques of human subjectivity amount to nothing less than the decentering of the subject [...] the critiques of Peirce, Lacan, Foucault, and Derrida (to name but four of the most important theorists in this regard) drive toward the decentering of the subject [...] these critiques move practices (especially an interwoven array of signifying practices) from the margins to the center of theoretical attention. In brief, they establish the centrality of practice." (Colapietro 2003, 68, 69).

12 "In my judgment, the most important of those implications is the decisive shift of theoretical attention to questions of practice: the decentering of the subject means, above all else, the centrality of practices, in their materiality, plurality, historicity, and thus mutability." (Colapietro 2003, 64). 
[...] os esforços sustentados dos atores corporalizados. Agentes de carne e sangue compõem e cantam canções, coreografam e dançam, escrevem e leem poemas, tiram e examinam fotografias, fazem amor e lutam guerras. A presença palpável de agentes somáticos assim como os traços desta presença são centrais na minha compreensão da subjetividade. Portanto, o que quer que signifique o descentramento da subjetividade humana, isto não significa para mim o apagamento do agente somático. (Colapietro 2003, 61 , tradução nossa). ${ }^{13}$

Nesse contexto, o autor evoca o aspecto somático, ao invés de sugerir um anulamento ou descentramento do sujeito em redes de esferas múltiplas. Esse aspecto somático pode ser trazido à discussão de múltiplos modos. Nas entrevistas que fizemos com os cantores, foi possível constatar que especificidades somáticas se mostraram significativas, até mesmo centrais, quanto a aspectos de mutabilidade e organicidade em relação a construções de sentidos e expressões vivenciados nas suas criações vocais. Foi possível verificar de que modos os elementos somáticos específicos vivenciados pelos cantores contribuíram nas suas relações com os elementos da partitura e a construção de fluxos dinâmicos de expressão, e em seu papel de agente comunicativo, tal como delimitado por Colapietro.

Assim, para o tenor entrevistado, os andamentos dados (ou afford) podem variar e ficar mais rápidos ou mais lentos em função de seu estado corporal. Para a soprano 2 , as respirações da peça podem vir a interferir no fluxo vocal em situações que ela precise cantar mesmo que esteja com o corpo debilitado. A soprano 1 indicou a possibilidade de estar com poucos graves na voz quando fosse interpretar e, por causa disso, não os valorizaria nessa circunstância. Mas, para os três cantores, essas variações físicas devem modificar a interpretação, ou seja, uma dificuldade físico-vocal transmuta-se em um elemento de expressividade:

Tenor: [...] um dia ele [o cantor] está melhor no outro dia ele está pior. Interfere, num momento que você não está tão bem, ou você quer correr, ou você quer diminuir [o andamento]. É importante as pessoas saberem isso. O bom artista, o bom intérprete, é aquele que usa tudo isso, e transforma numa coisa expressiva. (Tragtenberg 2012, 153)

Soprano 1: Aí acho o que mais influencia, claro que é o seu momento vocal, se eu estiver cantando isso aqui num dia que eu estou sem grave nenhum, eu não vou poder valorizar o grave, então eu vou ter que passar batido. Isso talvez signifique uma leitura diferente, uma interpretação diferente. (Tragtenberg 2012, 153)

Soprano 2: Já teve dias que eu não estava tão bem de voz, que eu estava saindo de gripe e tal. Aí, quando eu estou com o fôlego curto, eu respiro mais, quebra um pouco a frase mas, eu não deixo cair a bola, digamos eu tento fazer o possível. (Tragtenberg 2012, 153)

13 "[...] the sustained exertions of embodied actors. Flesh-and-blood agents compose and sing songs, choreograph and performances, write and read poems, take and examine photographs, make love and fight wars. The palpable presence of somatic agents as well as the traces of this presence are central to my understanding of subjectivity. Hence, whatever the decentering of human subjectivity means, it does not mean for me the erasure of somatic agency." (Colapietro 2003, 61). 
Portanto, considerando o sujeito em seu aspecto somático, parece ser possível também compreender que, embora nos processos de criação da interpretação os cantores tenham recorrido pouco a suportes externos para fazer anotações que contribuíssem para ela, as anotações ocorreram em "escritas" corporalizadas. Elas se deram com selfs atravessados por outras falas, agentes comunicativos em contextos sociais, históricos e culturais.

Resta-nos refletir sobre a natureza de alguns elementos envolvidos na percepção presente dos processos de criação do cantor, em seus dialogismos com a partitura e, de modo implícito, com o compositor.

\section{Percepção ecológica e a relação cantor-compositor}

A teoria da percepção ecológica foi desenvolvida no campo de estudos da visualidade, com referências também à sonoridade. Ela vem sendo utilizada em diferentes áreas de pesquisa, incluindo a música, como indica o lançamento do livro escrito por Eric Clarke, Ways of listening: an ecological approach to the perception of musical meaning. Essa teoria revelou o oposto do que compreendia o behaviorismo e o mentalismo, superando os conceitos preexistentes de estímulo-resposta. Gibson, em seu livro The senses considered as perceptual systems (1966) propôs a teoria de um sistema perceptivo que compreenda os sentidos como sistemas integrados e ativos, que busquem informação em movimento e orientem o percebedor, selecionando e organizando as informações.

Sendo possível caracterizar os objetos que são forçados sobre o cantor (como a partitura e os elementos sociais, históricos e culturais ligados a ela e ao compositor), também é possível verificar que o cantor se dirige em direção a eles, locomove-se, move-se, movimenta-se, percebe. Tal movimentação perceptiva nos leva a uma das compreensões de Gibson sobre a percepção:

Perceber é uma conquista do indivíduo, não uma aparição no teatro de sua consciência. É um estar em contato com o mundo, experienciando coisas ao invés de apenas ter experiências [...] percepção não é um ato mental. Também não é um ato corporal. Perceber é um ato psicossomático, não da mente ou do corpo, mas de um observador vivo. (Gibson $1979,239,240$, tradução nossa). ${ }^{14}$

Levaremos em conta o âmbito da teoria da percepção peirceana quanto à imbricação entre percepção, pensamento e ação, que propõe que:

Os elementos de todo conceito entram no pensamento lógico pelo portão da percepção e encontram sua saída pela porta da ação intencional; e o que quer que seja que não puder mostrar seu passaporte em ambos os portões deverá ser preso como não autorizado pela razão. (Peirce apud Salles 1990, 103).

\footnotetext{
14 "Perceiving is an achievement of the individual, not an appearance in the theater of his consciousness. It is a keeping-in-touch with the world, an experiencing of things rather than a having of experiences [...] perception is not a mental act. Neither is it a bodily act. Perceiving is a psychosomatic act, not of the mind or of the body but of a living observer." (Gibson 1979, 239, 240).
} 
A este âmbito, aditamos o conhecimento imbricado diretamente na sensibilidade, que diz respeito ao aspecto psicossomático indicado por Gibson e anteriormente, por Colapietro. Partindo disso, salientamos um elemento da citação acima: a dimensão ativa do indivíduo envolvida na constituição do ato perceptivo. Nela, o "estar em contato" (ou a sintonização, como propõe o autor) com o contexto experiencial citado nos parece um ponto significativo nas redes de processos criativos e interpretações vocais. Notamos que, na citação de Gibson, a "aquisição" perceptiva está configurada em um contexto ativo, no qual adquirir não significa obter algo que tenha sido apenas "jogado" à consciência do sujeito, que possa ter sido colocado ali e seja apenas recebido como um embrulho dado às suas mãos. A "aquisição" está intrinsecamente ligada às ações, informações que são captadas por um sujeito - denominadas pelo autor como pickup -, denotando sua atividade, sua atuação junto ao ambiente. O processo de pickup também se dá nos processos criativos do cantor na performance diante do público e no período de ensaios, orientado por seus propósitos e tendências direcionadoras integrantes de seu projeto poético.

Os conceitos de affordance e invariante, desenvolvidos na teoria da percepção ecológica, são trazidos à reflexão por se referirem a uma instância relacional contemplada nessa teoria, envolvendo significado e mutualidade. Esperamos que esses recursos da percepção ecológica possam trazer uma maior complexidade ao entendimento dos processos criativos da interpretação vocal, especialmente quanto ao instante de encontro entre o cantor e os elementos grafados na partitura, mutualidade que consideramos aqui como uma esfera relacional.

Abordando mais detidamente os conceitos de invariante, permanência e mudança ligadas à invariante e à variante, tal como utilizados pelo autor, ressaltamos que eles se referem à ecologia da percepção de tempo/espaço. Algumas características dos animais e do ambiente (podemos dizer também das partituras e das criações dos cantores) são invariantes/permanentes e, outras, são impermanentes/variantes. 0 ambiente é constituído por muitas informações de invariantes: "Quase nada é permanente para sempre: nada é também imutável ou mutável. Então é melhor falar de persistência sob a mudança."15 (Gibson 1979, 178). Desse modo, um evento possui invariantes e variantes, e a permanência é relativa, assim como a variação. No entanto, a permanência sustenta a mudança. Tal condição nos permite perceber a mudança, e permite a esta perceber a invariância. Gibson exemplifica a situação com elementos simples: ele indica invariantes de um quarto, que são, de algum modo, permanentes, levando em conta o teto e o chão. Mas, ele tem mudança constante quanto à localização dos móveis e à troca de roupas de cama, por exemplo. Segundo o autor, ainda é possível, em diferentes dias, reconhecer o mesmo quarto. O rosto de uma criança que chora se modifica e se mantém e, desse modo, estruturas invariantes se mantêm ali, ao mesmo tempo que se verifica variações.

Após experimentos nos campos da visualidade e da luz, o autor propõe que um “[...] objeto é especificado por invariantes sob transformação... eles são invariantes de estrutura." ${ }^{16}$ (Gibson 1979, 178). Não só objetos, mas pessoas, luz e som possuem invariantes de estrutura. Trazendo essa noção para o campo da música, Clarke (2005) aponta um exemplo de invariância em um tema musical (ou motivo) e suas transformações.

15 "Almost nothing is permanent forever: nothing is also immutable or changeable. So it's better to talk about persistence under change." (Gibson 1979, 178).

16 "[...] an object is specified by invariants under transformation... they are invariants of structure." (Gibson 1979, 178). 
Assim, o tema é apontado como uma invariante, pois reaparece diversas vezes e seus padrões de proporções temporais e de alturas não se alteram. Em vista disso, em meio às variações, ele estaria inalterado. Clarke cita o comentário de Dowling e Harwood sobre os diversos níveis de invariantes, como o famoso desenho rítmico-melódico iniciante da Quinta Sinfonia de Beethoven, e de invariantes em nível mais global, como gêneros de composição; em resumo, sobre o que podemos compreender como níveis na estrutura musical (micros, médios e macros).

A partir disso, faz-se possível a compreensão de que, na relação entre a partitura musical e o cantor, as invariantes ali grafadas sustentarão as variantes criativas do cantor. Trata-se de mudanças sobre invariantes. No caso do cantor, ele deve capacitar-se para captar a permanência, a relativa estabilidade, e ainda desenvolver a capacidade de entrar em contato com variantes, invariantes e affordances. Gibson indica que esse tipo de percepção se dá de modo direto e ativo. Para a área da psicologia, a conceituação da percepção direta, tal como realizada pelo autor, mostrou-se como algo novo. O que o autor indica é que, para o percebedor, as invariantes possuem informações que são diretamente captadas, ou detectadas, sem que seja necessária uma representação.

Entretanto, Gibson não afirma que esse processo se dê de modo consciente, e explica que, ao usar o termo "aware", não está se referindo a um processo consciente. O processo de captação da informação se dá, para Gibson, em um modo que ele denomina "sintonia", a partir da qual pode surgir um estado de ressonância com os affordances e propriedades do objeto. Outro conceito da percepção ecológica se refere à "educação de atenção" e, ainda, a um aprendizado que melhore a "sintonização", como, por exemplo a melhoria do paladar para uma determinada bebida, um processo que ocorre de modo direto. No processo de percepção artística, isso poderá ser compreendido no comportamento do "[...] artista [que] recolhe aquilo que o atrai..." (Salles 2010, 23):

Gibson havia dito que a "sintonização" é dependente da experiência que pode ser adquirida pela "educação da atenção". - Essencialmente, educar a atenção de alguém é refinar a habilidade de discriminar através da prática. (Davidson 1991, 36, tradução nossa) $)^{17}$.

O progresso do aprendizado é do indefinido para o definido, não da sensação para a percepção. Nós não aprendemos para ter percepções, mas para diferenciá-las. É neste sentido que nós aprendemos a enxergar." (Gibson apud Davidson, 1991, p. 37, tradução nossa) $)^{18}$.

17 "Gibson has said that "attunement" is dependent on experience which is achieved by the "education of attention". -In essence, to educate one's attention is to refine the ability to discriminate through practice." (DAVIDSON 1991).

18 "The progress of learning is from indefinite to definite, not from sensation to perception. We do not learn to have percepts, but to differentiate them. It is in this sense that we learn to see." (Gibson apud Davidson, 1991, p. 37). 
Indo nessa direção, perceber é também perceber a si mesmo: "O ato contínuo de perceber envolve a copercepção do self... * O próprio termo percepção precisa ser redefinido para permitir isso." (Gibson 1979, 240, tradução nossa) ${ }^{19}$.

No ambiente, os affordances são o que "[...] ele oferece ao animal, o que ele provê ou fornece, tanto para o bem quanto para o mal." 20 (Gibson 1979, 127, tradução nossa). Os affordances oferecem suas propriedades ao animal, que as percebe. Por exemplo, o chão, em sua dureza, oferece a possibilidade de caminhar em cima dele; a areia fina oferece, de modo direto, a informação da dificuldade para correr e andar sobre ela, devido as suas propriedades de superfície e de composição. Um cachorro agressivo dá informações de perigo. Os affordances informam ainda propriedades no campo da percepção emocional, as quais podem facilitar a adaptação e, desse modo, aumentar a chance de sobrevivência de quem as percebe. Significados seriam assim oferecidos e percebidos de forma direta pelo percebedor.

Portanto, com relação à criação no trabalho dos cantores, os affordances grafados na música são oferecidos a eles, devidamente criados pelo compositor e de modos específicos, organizados. Desse modo, entram no processo de captação, de contactar significados. Temos aqui um processo de mutualidade, em que o cantor entrará em contato com os elementos criados pelo compositor, as invariantes, os affordances presentes na parte musical, e vivenciará a partir deles o seu processo criativo. Com relação à seção $A$, um dos trechos da Canção de Amor, a soprano 1 indicou sentimentos quanto aos affordances melódicos e rítmicos do trecho:

Soprano 1: É ascendente, vão ficando mais aflitivos... Mais altos e mais aflitivos. Eu acho que ele coloca isso para mim. É essa sensação que eu vejo nessa progressão. (Tragtenberg 2012, 70, grifo nosso).

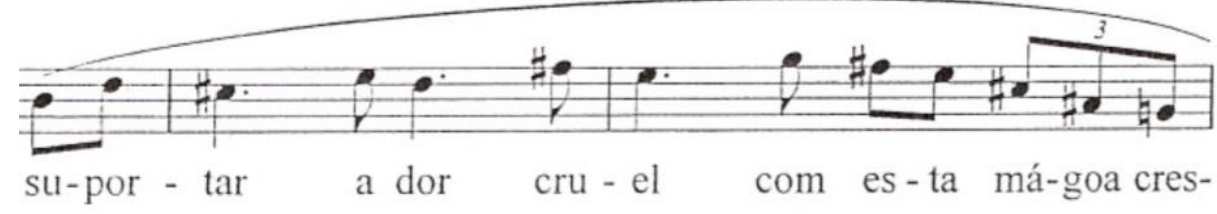

Figura 1. Trecho da Canção de Amor, de Villa-Lobos, ao qual a Soprano 1 se refere acima

Na citação, a cantora indica uma situação de oferta (affordance) e correlaciona alturas mais agudas e curva melódica ascendente com a aflição, sentimento coligado por ela. Portanto, as alturas com o movimento ascendente foram associadas a um sentimento de aflição, e esse trecho foi assim interpretado pela cantora em sua performance frente ao público. De forma mais específica, essas alturas, criadas de modo subsequente em direção aos agudos, foram um affordance para sua interpretação. A soprano 2 se refere explicitamente à sensação que teve (além das sensações advindas do poema da peça), relacionada a uma situação de comunicação da música, a qual, ao mesmo tempo que sugere algo, também pede algo ao cantor:

19 "The continuous act of perceiving involves the coperceiving of the self... * The very term perception must be redefined to allow for this fact." (Gibson 1979, 240).

20 "[...] it offers to the animal, what it provides or furnishes, either for good or ill." (Gibson 1979, 127). 
Soprano 2: A gente sente que são palavras-chave dentro da frase, do verso e a partir daí então que eu construo, às vezes, a frase toda, até a palavra dor. Então tem que dar uma sensação, emitir uma sensação, ansiedade. Mas o que, eu acho também a melodia ela pede, eu acho que nessa progressão "la ra ri, na ri nari" [cantarola o trecho relativo ao trecho do texto "suportar a dor cruel"] ela pede um movimento, ela pede, a própria música, as vezes, ela sugere ou pede enfim, esse movimento ou os ritenutos, rallentandos, eu acho que isso também, e eu sentia as vezes isso, a música está pedindo isso (Tragtenberg 2012, 71 , grifos nossos).

Poderíamos compreender apenas uma comunicação diferenciada na fala citada acima, mas, na realidade, trata-se do processo de captação/pick up de affordances rítmicos, melódicos e de andamentos.

A partir da citação, foi possível perceber ainda que a oferta dos signos grafados na parte musical pode vir a ser captada e compreendida em função do material concreto em seus elementos e estruturas, compreendidos como balizas semânticas, affordances de qualidades. Estas balizas e affordances se mostram colaborativos com as criações da interpretação em reciprocidade criativa. Esse é também o campo das interconexões (Salles 2011), um campo relacional de interações ausentes de hierarquização, como define a crítica de processos.

Invariante, nesse contexto, diz respeito a duas caracterizações: primeiro, nomeia a situação de permanência irredutível no oferecimento das affordances (características, possibilidades), que pode ser compreendida como a permanência concreta e durável da partitura, na qual os elementos são sempre os mesmos e estarão disponibilizados para quaisquer cantores, note-se, de fato quaisquer, que venham a entrar em contato com eles. A segunda caracterização diz respeito à Canção de Amor e aos gêneros musicais de choro e seresta, compreendidos como uma dimensão macro, tal como indicado por Dowling e Harwood na citação de Eric Clarke (2005) indicada na pág. 14 deste artigo. Os dois gêneros musicais contemplam uma multiplicidade de invariantes. Em nossa pesquisa de doutorado, todos os cantores relataram ter realizado essas correlações com a Canção de Amor: o baixo-barítono e o tenor a interconectaram ao choro e à seresta, a soprano 1 a conectou apenas à seresta, a soprano 3, ao choro, e a soprano 2, à música romântica, partindo da articulação vocal ligada e do poema. Essas relações foram estabelecidas também com base em informações externas à partitura, que não estavam ali grafadas nominalmente e eram oriundas de redes histórico-culturais circundantes à partitura, ao compositor e aos cantores, que dizem respeito também aos gêneros de seresta e choro.

Se considerarmos um nível médio, este pode ser apontado como uma invariante. Ela pode ser considerada, por exemplo, como a forma da peça, que é A B A'. Em nível micro, podem ser considerados os desenhos rítmico-melódicos e harmônicos e, ainda, o poema da canção. Mas, ao partirmos das invariantes escritas, teremos um nível de variações que só se tornará real quando o fluxo sonoro da voz do cantor se fizer audível e vier, assim, a transcriar em som audível, os affordances de andamento, intensidade e articulação grafados na partitura. Seriam eles, a saber: o Molto Lento, Piu Mosso, Lento, quasi Allegro, dinâmicas de intensidades sonoras (sons fracos/piano, meio fortes e fortes) e arcos de articulação. Essas evidências que implicam de forma conectiva uma memória e imaginação sonora, estão presentes também na fala do tenor: 
Tenor: A forma dela, o que ela soa pra mim, independente da letra, mais parece um violão, TUTITAPOPAPAPEPOU [cantarola a Introdução], parece que é uma coisa típica de choro e tal, é um improviso. (Tragtenberg 2012, 102, grifos nossos).

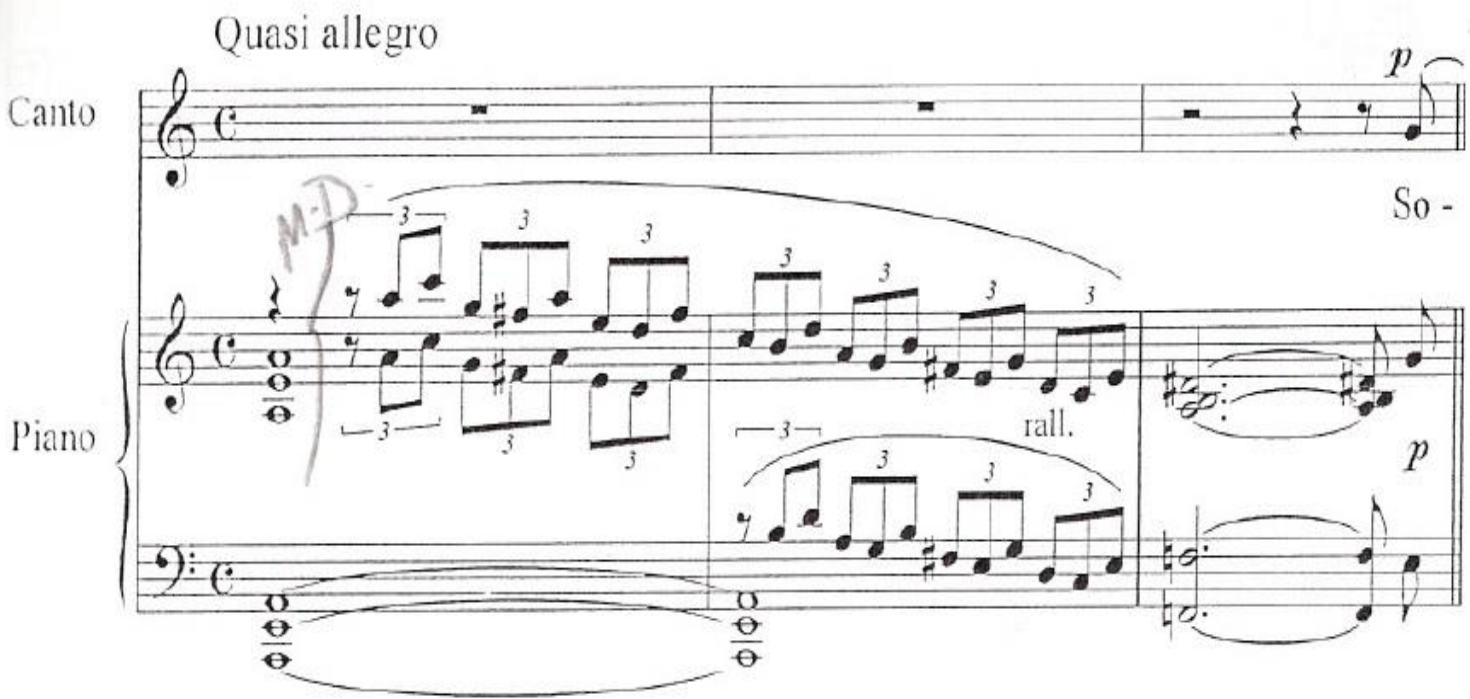

Figura 2. Introdução da Canção de Amor, de Villa-Lobos.

Mão direita e segundo compasso da esquerda fazendo o desenho descendente compreendido como violão por um dos cantores

Além de perceber o desenho rítmico-melódico escrito para o piano como sendo o de um violão tocado em gênero de choro, o tenor o compreende como um recurso de composição musical: o improviso. E, assim, ele indica ter vivenciado essa introdução em suas performances junto ao público, no que diz respeito aos affordances rítmico-melódicos e à harmonia dessa parte. É bom lembrar que o improviso é um elemento comum ao choro, como indica o musicólogo José Maria Neves: “[...] o 'choro' se aproxima do Jazz pelo seu caráter improvisativo, que exige dos intérpretes perfeito domínio de seus instrumentos." (Neves 1977, 23). O tenor compreendeu também na Introdução, o caráter de performance:

Tenor: RIDARIDARIDATITATITAPLAPLOM [cantarola a Introdução], só no final, é que mais ou menos ele estabelece, ele repousa... ela é performática nesse aspecto. (Tragtenberg $2012,103)$.

Posto isto, faz-se necessário investigar a constituição dessa curva melódica e de seu ritmo, seus affordances em variantes e invariantes para o cantor, para que seja possível compreender quais elementos levaram o tenor à sua convicção performática e, desse modo, a essa vivência interpretativa dessa parte da canção como performática. O trecho em questão tem uma curva melódica descendente, de alturas arpejadas sucessivas, em tercinas, oferecendo assim um ritmo ágil a ele, uma vez que a sonoridade forte, indicada na partitura, é um affordance de sonoridade potente. Esse desenho ágil e potente foi, portanto, associado à ideia de performance, e isso pode ter ocorrido devido à proximidade que tem com os improvisos instrumentais, geralmente realizados com grande destreza técnica, rapidez e potência considerável de elementos rítmicos e melódicos. Outro affordance grafado na parte musical parece ter contribuído para tal entendimento, o quasi Allegro, anotado no início da música: 
Tenor: RIDARIDARIDATITATITAPLAPLOM, [cantarola a Introdução rápida $e$ direta, sem pausa]. Soa um improviso de um violão, que não sabe nem em que tom vai começar! Só no final, é que mais ou menos... ele repousa. (Tragtenberg 2012, 103).

Apesar do andamento não ter sido diretamente citado pelo cantor, ele é evidente em sua concepção de performance improvisatória. Aditamos a informação de que os exemplos dados na entrevista foram cantados em um andamento rápido. Propomos, novamente, que elementos musicais e de texto escritos na parte musical oferecem proposições, ou seja, affordances, invariantes e variantes. Indo nessa direção, o que foi criado pelo compositor e é "dado" (afford) ao cantor, é um limite oferecido para ele, um limite criador e flexível, e não um limite restritivo, tal como apontado por Cecilia Salles (2010).

Verificou-se que uma introdução instrumental escrita para piano, em função de seu ritmo e andamento rápidos, aliados a informações de caráter histórico e cultural do compositor, levaram esse cantor a vivenciar essa parte da música como um violão, em um improviso musical performático, no estilo do chorinho.

Adentrando um pouco mais em modos relacionais na criação interpretativa vocal, trazemos o conceito de mestiçagem partindo de obras de Amálio Pinheiro (2009) e da de François Laplantine e Alexis Nouss (2002):

[...] não lhes é suficiente o hibridismo, pois que à mestiçagem não interessam apenas as proximidades e aglomerações de fronteira, mas principalmente as inclusões e conexões sintáticas, através de todos os procedimentos, de toda e qualquer linguagem, que transformam o separado, seja distante ou contíguo, em retículas ou labirintos de alteridades em ação e reação. (Pinheiro 2009).

Ora, a mestiçagem contradiz precisamente a polaridade homogéneo/heterogéneo. Ela oferece-se como uma terceira via entre a "fusão" totalizadora do homogéneo e a fragmentação diferencialista do heterogéneo. A mestiçagem é uma realidade complexa, cujos componentes mantém a sua integridade. (Laplantine e Nouss 2002, 80).

Com isso, considera-se que o cantor, o compositor e a partitura, juntamente com as informações de suas redes biográficas e sócio-histórico-culturais, vão sendo complexamente entretecidos em alteridades tramadas a partir da sintaxe, mas sem que haja fusão ou síntese, uma vez que eles mantêm sua integridade. Nesse ponto, é possível falar em uma qualidade relacional específica cara aos processos de criação do cantor.

Desse modo, tivemos contato com várias versões mestiças da Canção de Amor. Nelas, reconhecemos o cantor e o compositor, que não se fundem em uma só unidade. Temos, assim, muitas interpretações de uma mesma música, e a reconhecemos em sua unicidade em cada interpretação diferente. Há, portanto, um trânsito constante e mestiço, que garante uma qualidade relacional no trabalho de interpretação do cantor, levando em conta também os conceitos de mutualidade de Gibson e o de reciprocidade criativa. 


\section{Considerações Finais}

Retomando a dimensão ativa da atuação criativa do cantor realizada a partir dos elementos grafados na partitura pelo compositor, a perspectiva da mestiçagem (Laplantine 2002), na condição de reciprocidade criativa, apresenta a constante característica da mutabilidade recíproca. Esta se dá como a qualidade relacional de estar em trânsito, ou trânsitos, mantendo conexão permanente em trocas processuais, mas, o que é muito importante, ausentes de sínteses redutoras a uma única parte.

Como vimos em nossa análise acerca do Umwelt psicológico, social e cultural ligado aos processos de criação de cantores em diálogo com os de compositores, esse conceito de base biológica da semiótica trouxe à discussão uma amplitude de elementos para a análise do universo da criação na música, apontando para a necessidade de aprofundamento da investigação considerando a diversidade de Umwelten criativos.

Desse modo, a investigação deve se direcionar ao Umwelt próprio aos compositores, como a dimensão relacional do compositor com os suportes em seus processos de criação e sua consciência de que sua ação final é incluir sua criação em uma partitura, e não o diálogo direto com o público. Ela deve se direcionar também ao Umwelt próprio aos cantores - sua ênfase corporal e a consciência da apresentação de sua criação em performances ao vivo. Esses dois Umwelten podem ser compreendidos, como indica Uexküll, como habilidades neurológicas, empíricas ou teóricas, e estilos artísticos diversos.

A questão da singularidade quanto ao universo de compositores e cantores nos levou aos atravessamentos do sujeito e do self, conceitos da semiótica de Peirce, que os compreende como processos semiósicos que resultem em um estado de crescimento constante.

A caracterização do self como um agente comunicativo, feita por Colapietro, que modifica a possível noção de isolamento do sujeito em si mesmo, levou-nos diretamente à questão da alteridade inscrita na subjetividade, de acordo com a compreensão do autor quanto ao self peirceano. Esta foi fundamental para a compreensão de falas que atravessam o sujeito e de sua dimensão comunicativa. Ela pode ser apontada no trabalho criativo do cantor e, desse modo, ser desvelada como um dos possíveis nós de sua rede de criação interpretativa. Seguimos a compreensão dos processos de criação artística em rede, como os conceitua Cecilia Salles em Redes da Criação: “[...] como rede de conexões, cuja densidade está estreitamente ligada à multiplicidade das relações que a mantém." (Salles 2006, 17).

Os affordances e o conceito de mutualidade com que caracterizamos acima os eventos de interpretação vocal dos cantores da Canção de Amor, feitos com base nos elementos musicais criados pelo compositor, trouxeram uma luz específica para a questão da criação interpretativa do cantor e contribuíram para nomear de modo claro aspectos da percepção que se estabelecem em tal situação.

Isso se deu no caso do tenor, em que os affordances dos desenhos rítmicos e de alturas na melodia, assim como o do andamento, explicitaram a ele as informações desses elementos musicais e o levaram a compreender uma introdução instrumental feita por um piano como se fosse feita por um violão. E, por causa dessa percepção, ele se aproximou do universo da seresta brasileira, trazendo esse elemento para sua interpretação da canção. 
A concepção de escrita e escritura de Zampronha, sob a perspectiva peirceana, trouxe a compreensão da dimensão significativa de utilização do espaço corporal como espaço de escritas por parte do cantor, mais do que o espaço dos papéis (a partitura ou os cadernos), tal como o é para o compositor.

Essa definição de escrita e escritura nomeou estados corpóreos e proporcionou a indicação de estados diversos entre cantor e compositor em seus processos de criação. Nesse jogo mestiço constante, para manter o contato entre cantor e compositor em sintaxes constantes, algumas das atuações por parte do cantor pareceram ser: a de captar, perceber e atuar com sua percepção ecológica; e a de trabalhar com pensamentos lógicos, em interações com a memória, imaginação e sensação. Tudo isso atravessado por outros falantes, em diálogos inter e intrapessoais, sob a égide da semiótica peirceana.

Esperamos ter contribuído para um acesso às partituras internas dos cantores, em um cenário de mutualidade e reciprocidade, que consideramos fundamentais para pensar os processos de criação vocais.

\section{Referências}

Clarke, Eric. 2005. Ways of listening: an ecological approach to the perception of musical meaning. New York: Oxford University Press.

Colapietro, Vincent Michael. 1989. Peirce's approach to the self: a semiotic perspective on human subjectivity. Nova York: State University of New York Press.

. 2003. "The loci of creativity: fissured selves, interwoven practices". In Manuscrítica revista de crítica genética 11. 59-82.

Davidson, Jane. 1991. The perception of expressive movement in music performance. Tese de Doutorado em Filosofia. Londres: Departamento de Música da City University. 367 p.

Ferraz, Silvio. 2007. Notas, atos, gestos. São Paulo: 7 Letras.

Gibson, James J. 1979. The ecological approach to visual perception. Boston: Houghton Mifflin.

Gibson, James J. 1966. The senses considered as perceptual systems. Londres: George Allen \& Unwin Ltd.

Laplantine, François, e Nouss, Alexis. 2002. A mestiçagem. Lisboa: Instituto Piaget.

Lockwood, Lewis. 2005. Beethoven: a música e a vida. São Paulo: Conex.

Pinheiro, Amalio (Org.). 2009. O meio é a mestiçagem. São Paulo: Estação das Letras e Cores.

Salles, Cecilia. 2010. Arquivos de criação: arte e curadoria. Vinhedo: Editora Horizonte.

2008. Crítica genética: fundamentos dos estudos genéticos sobre o processo de criação artística. São Paulo: EDUC.

2011. Gesto inacabado: processo de criação artística. São Paulo: Intermeios.

. 2006. Redes da Criação: construção da obra de arte. Vinhedo: Editora Horizonte.

Tragtenberg, Lucila. 2012. Processos de criação da interpretação vocal em rede. Tese de Doutorado. São Paulo: Pontifícia Universidade Católica. 208 p. 
Vieira, Jorge A. 2008. Teoria do conhecimento e arte. Fortaleza: Expressão Gráfica e Editora. 2009. "Teoria do conhecimento e arte". In Música Hodie 9 (2). 15.

Zampronha, Edson. 1998. Notação, representação e composição: um novo paradigma da escritura musical. Tese de Doutorado. São Paulo: Pontifícia Universidade Católica. 291 p. 